'Lean', new technologies and employment in public health services: employees' experiences in the National Health Service

Colin Lindsay, Department of Human Resource Management, University of Strathclyde

Johanna Commander, Department of Human Resource Management, University of Strathclyde

Patricia Findlay, Department of Human Resource Management, University of Strathclyde

Marion Bennie, Strathclyde Institute of Pharmacy and Biomedical Sciences, University of Strathclyde

Emma Dunlop Corcoran, Strathclyde Institute of Pharmacy and Biomedical Sciences, University of Strathclyde

Robert Van Der Meer, Department of Management Science, University of Strathclyde 


\section{'Lean', new technologies and employment in public health services: employees' experiences in the National Health Service}

\section{Abstract}

This article considers employees' experiences of a major organisational redesign project, which sought to deploy robotics technologies to improve the performance of National Health Service pharmacy distribution in one part of the UK. The principles of Lean-type approaches partly informed the redesign project, with senior managers seeking to tap the benefits of new technologies to streamline processes, while also arguing that change would bring opportunities for up-skilling and inter-professional collaboration. The project managed to avoid some of the negative consequences for job quality predicted by the critical literature on Lean-type approaches in public services. However, employees' experiences varied, with some reporting new engagement in learning and collaborative service delivery 'nearer the patient', while others complained of fewer opportunities to rotate across a variety of job roles. More fundamentally, employees questioned management's assumption that new technologies and Lean-type approaches are crucial to improved performance and better jobs. For many employees, both performance and job quality were compromised by the 'leanness' of staffing models, which limited opportunities for development and contributed to work intensification. This tension is likely to remain a key theme in employment relations in the UK and beyond for as long as the public sector faces financial austerity. 


\section{Introduction}

'Lean' management tools have been widely promoted as effective in driving down costs and improving efficiency across a range of organisational contexts. Although more often deployed in the private sector, Lean has also gained acceptance as a public management reform tool, arguably reflecting the broader logic of the 'New Public Management' (NPM) agenda in countries such as the UK (Carter et al. 2013). In some areas of the UK public sector, such as the public health services provided by the National Health Service (NHS), there have been attempts to transfer specific Lean management tools - such as 'value stream mapping' - to work organisation and the delivery of services (NHS Institute 2008). It might also be argued that the more general principles and philosophy of Lean have informed a broader range of workplace and service redesign projects in the NHS (Radnor et al. 2012). However, there remains debate as to the appropriateness of Lean-type approaches as a tool for improving performance and work organisation in public service organisations (Radnor and Osborne 2013). Specifically, there are concerns that, despite rhetoric suggesting that Lean can empower employees to get involved in organisational reform, many individuals report experiences of increased work intensification and reduced job quality following such reform programmes (Carter et al. 2011a).

This article considers employees' experiences of a major organisational redesign project, which sought to deploy robotics technologies to improve the performance of NHS pharmacy distribution services in one part of the UK. It is clear that the principles of Lean-type approaches partly informed the redesign project, with senior managers seeking to tap the benefits of robotics technologies to streamline 
processes, while also arguing that change would bring new opportunities for upskilling and inter-professional collaboration for employees. Our research draws upon debates around the potential benefits and drawbacks of Lean-type approaches for public service employees in order to frame an analysis of in-depth interviews with NHS staff and managers. The article particularly focuses on employees' experiences of redesign processes, in order to assess claims made in the HRM literature - both positive and negative - as to the potential for Lean-type approaches to impact on experiences of work intensification, autonomy and other aspects of job quality. Accordingly, 36 in-depth interviews covered issues around: management-employee communication and consultation on the redesign process; resulting changes in opportunities for learning and progression; and impacts on job quality and especially work intensification. As noted below, these themes are all key areas of debate about Lean's capacity to promote progressive change in the employment relationship, or alternatively its role in imposing top-down managerialist reform in public sector organisations.

Following this introduction, we present a review of literature on Lean-type approaches in relation to work organisation and employment relations, and in the context of broader NPM agendas in the public sector. It is important to note here that our literature review does not seek to provide a systematic assessment of the impact of Lean on job quality in public services or other contexts. Such a systematic review is beyond the scope of this article and, at any rate, a major thrust of our analysis and conclusions is that the context for specific Lean reforms is key to their impact on the employment relationship, and that the experiences of different employees is likely to be variable. We then describe the policy and organisational context for our primary 
research, focusing on the redesign of work organisation based on the introduction of robotics technologies in NHS pharmacy distribution services; and summarise our methodology. We present the findings of in-depth interviews with NHS employees and managers regarding the impact of redesign processes on experiences of work organisation and job quality. Finally, our conclusions offer some critical reflections on the appropriateness and impacts of Lean-type approaches in public services.

\section{Lean, NPM and employment in public services}

\section{Lean-type approaches and NPM}

Lean management reforms were initially established in the auto-manufacturing sector, but have since been adopted within many service sector organisations (Maroto-Sanchez 2012), including in the management of public health services (Radnor et al. 2012). The term 'Lean' tends to be deployed in a number of contexts and with reference to a range of meanings. Womack and colleagues' seminal works (see, for example, Womack et al. 1990) initially identified a number of 'Lean principles' focusing on: specifying value for the customer; identifying related value streams and challenging 'wasted steps' within those processes; the standardisation of processes around best practice to promote continuous flow and pull-through processes; and 'managing towards perfection so that non-value adding activity will be removed' (Radnor et al. 2012: 365). Emerging from efficiency programmes developed within Toyota and other auto-manufacturers, specific Lean management tools seek to promote continuous improvement and process standardisation (Womack et al. 1990). However, as we will see below, what might be called 'Leantype approaches' have also been adopted by managers who, while discarding some 
of the specific reform methodologies advocated by Womack and colleagues, buy in to Lean's broader philosophy of waste-elimination.

Bonavia and Marin-Garcia (2011) note that the relationship between Lean and HRM (and more generally Lean's impact on the employment relationship) was initially a relatively marginal issue in seminal works on the subject. Yet, given Lean's focus on teamwork, multi-skilling and flexibility as essential tools in driving efficiency and eliminating waste, it has been argued that both employees' expert knowledge and their commitment to change are necessary conditions for the success of reforms. For example, Sterling and Boxall's (2013) research within a high performance manufacturer found 'strong learning' outcomes (and improved satisfaction among employees) associated with Lean where managers and employees collaborated effectively on reform processes; but reported experiences of work intensification elsewhere in the organisation as a result of a lack of support for learning among lower-skilled staff, and scepticism among line managers. Furthermore, among a range of management tools that have been deployed regularly as part of Lean, many focus on changes to work organisation, such as the standardisation of work activity through 'standard operating procedures' to eliminate variation; the reduction of 'justin-case' staff 'buffers' (i.e. downsizing); and training to facilitate multi-skilled teamworking (Bonavia and Marin-Garcia 2011)).

Finally, the HRM dimension of Lean also matters because, when such managerialist reform agendas fail, it is line managers and employees who tend to get the blame. Accordingly, for Radnor and Boaden (2008: 5) 'barriers' to Lean implementation in public services include the 'lack of a clear customer focus' and 'staff working in silos'. 
Elsewhere, 'a lack of commitment from senior management' (Radnor and Osborne 2013: 269), and public sector professionals' resistance to 'attempts to make their work more predictable, transparent and standardised' (Radnor and Osborne 2013: 273) have been seen as problematic.

This brings us to the place of Lean-type approaches within broader NPM reform agendas in public services. Public service employment in the UK and many other advanced welfare states has been subject to sustained reform processes since the 1980s. The core values of NPM - with a strong emphasis on individual performance monitoring, cost control and the empowerment of 'hands on' managers - have inevitably impacted on people management and work organisation in public service workplaces (Bach and Givan 2011). These NPM values clearly fit well with Lean, and Lean-type approaches also became increasingly common in organisational reform strategies in the UK public sector during the 1990s and 2000s (Radnor 2010).

Advocates of Lean have argued for the transferability (from manufacturing to public services) of its key themes of designing out over-burdened, inconsistent and wasteful operational processes (Radnor and Osborne 2013). In some public organisations, including areas of the NHS, a range of Lean interventions have been advocated, so that managers are encouraged to shoehorn techniques developed in manufacturing contexts - such as 'value steam mapping' (which involves teams systematically identifying steps in work processes that add value and eliminating wasteful ones) - into complex public services (Radnor and Boaden 2008). Such Lean tools have informed clinical process redesign initiatives - with some evidence of efficiency benefits - in health services in the UK and elsewhere (Bon-Tovim et al. 
2007). However, broader evidence reviews of the impact of NPM tools, including Lean, in the NHS have been critical of their effect on the quality of services (Simonet 2013). There is also evidence that the fragmentation of management and elaborate performance regimes that come with NPM have resulted in additional costs, undermining claims made of efficiency gains (Pollitt 2013).

More recently, public sector managers have been flexible - perhaps even vague - in their exposition of the principles of Lean. In this reading, Lean is more a "philosophy of continuously improving services by either increasing customer value or reducing non-value adding activities, process variations and poor work conditions' (Radnor et al. 2012: 365). Often, the overarching Lean principles outlined by reforming managers amount to little more than a set of incontestable positive aspirations. For example, Radnor (2010: 416), reporting management's 'pitch' on Lean to employees in Her Majesty's Revenue and Customs (HMRC), found uncontroversial aims such as 'to improve productivity, quality and reduce lead time [and] to create appropriate management infrastructure to sustain improvements'.

The adoption of what we will call hereafter Lean-type approaches, based on a broader set of values and principles, may reflect a more general softening of the Lean agenda as its advocates have sought to argue for its relevance to service sector contexts. The 'shift from a specific to a more generic Lean definition' (Carlborg et al. 2013: 294) reflects an acknowledgement that driving down costs and promoting standardisation in services may not always result in better quality outcomes and higher levels of satisfaction among end users. Similar attempts have been made to humanise the Lean agenda within public services - Radnor and Osborne (2013: 
282) argue for Lean to be adapted away from its micro-level focus on internal processes to become 'a holistic theory of service delivery'. The suggestion here is that some elements of Lean-type approaches can be retained, while the overall focus should shift towards holistic, patient-centred care (Radnor and Osborne 2013), reflecting a broader acceptance of 'post-NPM' approaches to managing public services (Osborne 2010). However, the language and values of Lean remain prominent in public sector reform strategies (McKinsey Center for Government 2012). This is important because there remains considerable controversy around the value of, and assumptions behind, Lean-type approaches in public service organisations, including parts of the NHS.

First, critics of Lean-type approaches may take issue with the underlying assumption that such NPM-oriented reform agendas are an urgently required response to a perceived crisis in existing models of organising public services. For example, research for the NHS Confederation (Jones and Mitchell 2006) arguably presents a depressing vision of organisational failure, with Lean and related NPM approaches seen as an essential corrective response. From this perspective, 'Lean can help save healthcare', while there is an assumption that non-Lean environments are inherently inefficient and that, given public investment in the NHS, 'improvements should have been more significant' (Jones and Mitchell 2006: 3). The evidence base for such statements is often thin or entirely absent, and this may explain why frontline staff (and operational line managers) can be sceptical as to necessity and value of Lean-type approaches. 
Similarly, those advocating Lean-type approaches in organisations such as the NHS often seem to start from the assumption that on-going organisational problems cannot be addressed with additional investment, but rather only through managerialist reform (Jones and Mitchell 2006). There may be a fundamental disconnect here between employees, who see their work as subject to stringent resource constraints, and managers who sometimes appear neutral as to whether 'it may or may not be true that the NHS needs more resources or lacks capacity' (Jones and Mitchell 2006: 15). The credibility of reform agendas will be undermined where the realities of resource constraints are not acknowledged.

Another fundamental area of controversy often raised by critics of Lean-type approaches is that their underlying assumptions reflect the norms of the manufacturing sector, and cannot easily be transferred to complex public service environments. Radnor et al. (2012: 365) acknowledge that the NHS presents a number of institutional challenges to the translation of management practices found within the commercial sector... [including] competing or contradictory political, regulatory or commissioning priorities; the persistence of powerful professional groups as manifest in specialist expertise, established ways of working and defined jurisdictional boundaries; and high degrees of organisational complexity'. Furthermore, Lean is about standardisation, and there is an acceptance 'within healthcare that the delivery of patient care is largely a human process and consequently that the causes of variability are often difficult to quantify' (Radnor and Osborne 2013: 274). 
The same underlying tension characterises the relationship between Lean-type approaches and people management in organisations like the NHS. As Bonavia and Marin-Garcia (2011: 933) note 'in Lean production, HRM aims fundamentally to support the standardisation of work processes [and] the minimising of deviations from these standards'. The extent to which employment relationships and work organisation in the NHS are open to exactly the same forms of standardisation remains a matter of debate. Complex service interactions (in public or private services) are defined by variability and diversity in what is required, with 'value' and quality rooted in the co-production of outcomes by service user and provider (Carlborg et al. 2013). Perhaps understandably, in the NHS and many other public service organisations, there has been resistance to the fragmentation and 'reengineering of working practices that were formerly based on professional independence and judgement' (Carter et al. 2013: 87). Indeed, the potential impacts (positive and negative) of Lean-type approaches on work organisation and employees' experiences of job quality in public services has been established as important field of public management research, and we now turn to some of the key themes emerging from this literature.

\section{Lean-type approaches and employee engagement in public services}

Advocates of Lean have argued that improved autonomy for employees can emerge from such reforms, while a commitment to consultation and engagement with staff during planning and implementation is an essential element of Lean 'good practice' (McKinsey Center for Government 2012). As Radnor and Boaden's (2008) review of evidence notes, where these elements are in place Lean has capacity to promote a sense of shared ownership and thus secure the buy-in and commitment of front-line 
staff. However, empirical studies of Lean in action in the public sector have found very mixed evidence on achieving employee engagement buy-in. Advocates have argued that Lean in the NHS 'engages the enthusiasm of front-line staff' (though this appears to based on the views of management) (Jones and Mitchell 2006: 6). Yet many studies of public employees' experiences of Lean-type approaches have concluded that change is viewed as being imposed from the top-down (Carter et al. 2012). Radnor's (2010: 420) research with HMRC employees on the receiving end of Lean found that many 'felt that they had not had significant involvement in the development of the processes... staff felt that Lean was imposed and that front-line staff had no real say in how it was implemented'. Further research in the same organisation reported how management characterised as negative, and tried to shut down, any employee criticism of Lean's impact on work organisation and job quality (Carter et al. 2011a, 2011b).

Public sector employees may be particularly resistant to buying-in to Lean-type approaches if they see process changes as part of an agenda focused on costcutting and especially staff reductions (Radnor et al. 2012). Advocates of Lean-type approaches can seem conflicted about the relationship between such process reforms and the perceived need to reduce staff numbers. The official NHS line has been that 'Lean is not about headcount reductions' (Jones and Mitchell 2006: 6), but also that an 'inevitable result of Lean is that fewer people are needed to achieve the same (or more) results' (Jones and Mitchell 2006: 21). Lean's champions similarly acknowledge the problem of buy-in in terms of 'persuading people to embark on a Lean journey where the last stop may be their own removal' (Radnor and Boaden 2008: 6). There are numerous examples of Lean-type approaches coinciding with 
programmes of headcount reduction in public organisations (Carter et al. 2012), but also cases where staff numbers have been maintained. The more general point is that, as noted above, Lean-type approaches can be seen by managers as a means of circumventing debate as to the need to invest in, or just maintain, staffing levels.

\section{Lean-type approaches and job quality in public services}

Supporters of Lean-type approaches have also consistently made claims of benefits in terms of job quality. Yet, it is accepted in the broader HRM literature that the evidence on Lean's impact on employment relations and job quality is distinctly mixed - 'while some argue that employees are empowered or upskilled, others suggest that Lean production makes for a more stressful, intense work experience, with limited or non-existent redistribution of responsibility and autonomy' (Currie and Procter 2003: 583). More specifically, the evidence on Lean's potentially positive impact on employment in service-based workplaces is patchy (Carlborg et al. 2013), and in public services even more mixed (Carter et al. 2013).

In the context of NHS reform, managers have argued for Lean's potential 'to make working lives less stressful and more rewarding for staff, and to boost productivity and efficiency...' (Jones and Mitchell 2006: 3). Some of the core principles of Leantype approaches may indeed be attractive to both employees and managers who have worked in large public organisations. The potential of Lean to transcend 'silo working' and overcome 'disconnects' between groups of employees may be valuable in public sector workplaces where professional boundaries and long-established departmental demarcations can undermine effective teamwork (Jones and Mitchell 2006). Lean's emphasis on clarity in visualising workflows may also appear attractive 
in complex public sector bureaucracies where multiple teams, professional groups and organisations contribute to outcomes. More generally, it might be argued that if Lean succeeds in eliminating duplication of effort and waste, then there may be benefits for employees 'freed' to pursue higher-value added tasks and opportunities for skills development.

Accordingly, advocates of Lean-type approaches claim that 'intangible benefits include cross-team synergies, and a rise in employee motivation and morale' (Radnor and Boaden 2008: 5). However, in some cases, motivational benefits appear so intangible so as to be non-existent in the eyes of public sector employees experiencing Lean. Radnor and Boaden (2008: 6), summarising evidence from five studies of Lean in the public sector, conclude that 'Lean systems can be seen as exploitative and high-pressure' by some employees. Carter et al.'s (2011a, 2011b, 2012) extensive research on the introduction of Lean-type approaches in HMRC involved the quantitative analysis of survey responses from 840 employees across six worksites, complemented by 36 in-depth interviews with line managers, staff and union officers. They identified a fragmentation of job roles, the prioritisation of narrowly defined performance targets (at the expense of overall service quality), declining control and discretion for employees, work intensification (reflected in, for example, restrictions on breaks from work), and resulting negative impacts on motivation, wellbeing and satisfaction. In this case 'a Lean-induced surge in sickness and absence' was met with stricter absence management strategies that pressurised employees experiencing ill-health to return to work (Carter et al. 2012: 425). The same research found that many employees had experienced deskilling as a result of 
the fragmentation and standardisation of their job roles, and that opportunities for training and progression had been curtailed (Carter et al. 2011b).

Finally, it has been argued that Lean-type approaches can offer benefits in terms of more coherent models for understanding and improving employee performance. Lean rhetoric around devolving problem-solving to teams and streamlining processes implies that there may be an opportunity to break free from intrusive and overly-bureaucratic forms of performance monitoring and reporting. This potential benefit may appeal particularly to NHS managers, who have been criticised for their complicity in the imposition of rigid performance management systems (often with a strong emphasis on targets and 'league tables') that have sometimes produced perverse incentives and resulted in 'gaming' (Exworthy 2010). However, champions of Lean-type approaches have struggled to differentiate Lean from the established machinery of NPM, within which stringent performance management regimes play a crucial role. For example, Carter et al.'s (2011a: 116) research on Lean in HMRC identifies 'the ideology of NPM': explicit performance metrics that are monitored intensively; 'hands on' management in the shape of enhanced supervision; and greater labour discipline. Elsewhere, even where employees have supported measures to improve 'customer service' as part of Lean, 'the focus on customer needs and staff motivation was sometimes lost by the pressure to achieve targets' (Radnor 2010: 420).

The discussion above stakes out some of the key controversies around the appropriateness of Lean-type approaches in public services, and the potential consequences for employees' experiences of work reorganisation and changing job 
quality. We have seen above that there remains considerable debate about the transferability of Lean principles to public service workplaces and implications for employees. There may be a disconnect between senior managers who see NPMtype managerialism as a panacea and employees who are required to implement a continuous stream of reorganisations in the context of severe resource limitations. The multiple priorities and 'customers' involved in public services, and the importance of professional knowledge, may limit the applicability of Lean-type approaches based on standardisation. And the rhetoric of Lean advocates around staff empowerment and improved job quality may conflict with some employees' experiences of top-down change and work intensification. These same debates were reflected in our interviews with NHS employees and managers. We now turn to the specific context for our research, before reporting the findings of these interviews.

\section{Context and methodology}

\section{Context for the research}

Our research was located within a large Health Board that is responsible for funding and managing healthcare (including pharmacy provision) in one area of NHS Scotland (Scotland's national public health provider, which employs more than 150,000 staff). In 2008 , the Board approved a major pharmacy redesign programme with objectives including to: redefine hospital pharmacy services around 'patients' own medicine', through new systems to store securely and manage patients' preprescribed and newly-prescribed medication at ward-level; and redesign, consolidate and automate hospital pharmacy medicines distribution, in order to release pharmacy staff to undertake near-patient tasks as part of integrated clinical teams. 
As we will see below, the extent to which pharmacy staff felt able to connect to the first of these objectives - supporting ward-based services to facilitate the management of patients' medicines at bedside (an initiative that we will abbreviate as 'MyMeds' hereafter) - was important in shaping views of the impact of the redesign programme on working lives.

As noted above, the introduction of new robotics technologies in the pharmacy distribution function was an integral part of this redesign. A key element in the implementation of the redesign programme was the construction of a new Distribution Centre (DC) to replace eleven different in-hospital pharmacy stores. The DC is now the single facility responsible for the procurement and automated distribution of medicines to replenish ward and site pharmacy stocks for all hospitals and community clinics in the Health Board area (approximately 4,000 destinations). Aligned to this automation project was a major organisational change programme with significant implications for jobs, work organisation and employees' experiences. This involved most employees being moved out of dedicated dispensaries at hospital sites. Instead, pharmacists and many technicians were moved 'nearer the patient' to smaller ward-based satellite dispensaries. Other staff were redeployed to the centralised DC. A key element of the DC's work is facilitated by robots that store, gather and distribute medicines in response to replenishment orders on a '24-7' basis. Within the DC, nine robots are programed to work in tandem as an integrated storage and distribution system. DC employees manage, maintain and facilitate the automated distribution processes. Finally, a minority of staff were retained to deliver the remaining support services provided by hospital dispensaries. 
A number of parallel rationales can be identified as informing the Health Board management's decision to take forward the pharmacy redesign programme. First, there was clearly an interest in promoting high quality, person-centred clinical pharmacy services 'nearer the patient', in line with the priorities of NHS and Scottish Government strategies (Scottish Executive 2006); and an assumption that robotics technologies, combined with work redesign, could facilitate such an approach. From NHS management's perspective, there is a win-win from such reforms, which can deliver better services for patients, and also improved skills utilisation (and more fulfilling working lives) for NHS employees. However, there were also arguably rationales that can be connected with the logic of NPM. For example, the redesign programme fitted with a broader agenda emphasising the need to evidence in quantitative terms (and perhaps even monetise) the contribution of NHS pharmacy services to clinical outcomes (Purkiss 2008). NPM themes around cost control and standardising and quantifying performance were clearly reflected in underlying business case for the redesign.

Furthermore, the Lean-type approaches that are often an important component of NPM (as discussed above) were reflected in values and content of redesign programme. NHS management has sought to promote Lean-type approaches across a range of areas of work and organisational contexts (Jones and Mitchell 2006; Radnor et al. 2012). For example, NHS Scotland's 'Efficiency and Productivity Programme' emphasises the 'strategic adoption of Lean' as a means of improving service efficiency, outlining measures to contract for technical expertise in Lean, provide training for relevant staff and managers and support the system mapping and data capture requirements of NHS organisations seeking to undertake related 
redesign processes (Scottish Government 2011). The same programme of activities supports a 'Lean Transformation Network' among senior territorial NHS Board managers to share good practice. Lean is therefore an important overarching theme for management and work redesign initiatives across NHS organisations.

Indeed, the organisational redesign programme that provided the focus for our research was clearly influenced by Lean thinking. Line managers reflecting on recent organisational reforms suggested that they could now report to senior management that: "we've done as much lean working as we can do; we've chopped and changed as many processes as we can..." (Senior Technician). For one pharmacist, it was clear that management had sought "to challenge the pharmacy distribution centre to become as lean as it possibly can..." (Pharmacist). Accordingly, while certain specific management tools associated with Lean were absent from this redesign programme, it appears that some of the principles and ideas of (and controversies around) broader Lean-type approaches were present in this case. Specifically, work process redesign was introduced as a means maximising efficiency, establishing more productive teams around automated processes, and achieving improved performance without additional staff costs.

\section{Methodology}

A multiple stakeholder approach was used to deliver a balanced understanding of the redesign programme and its implications. This was a qualitative study, and appropriate investigative tools were developed and piloted, including an interview schedule and timeline detailing landmark events to facilitate participant recall of their work-related experiences since 2008. Interviews with employees particularly focused 
on experiences of the redesign programme and impacts on jobs and working life. The interview questions were semi-structured enabling interviewers and interviewees to expand on areas deemed useful.

The employee-focused element of the research involved interviews with 36 staff, which included six pharmacists, sixteen pharmacy technicians and fourteen support workers. As noted above, the redesign programme and linked MyMeds project sought to re-centre the work of NHS pharmacists (many of whom had previously been based in hospital dispensaries) on the delivery of ward-based, patient-facing services. To support these changes, pharmacy technicians were redeployed to three main roles: the delivery of MyMeds at ward-level (arranging prescriptions for, and gathering information from, patients; and supporting the work of ward-based pharmacists); supervising the large-scale distribution function at the DC; and maintaining hospital dispensaries, which continued to provide prescriptions for outpatients and a hospital-level link in the supply chain between wards and the DC. As with the technicians, support workers were redeployed between the wards, the DC and hospital dispensaries, in support roles including: data entry for medicines orders; organising, storing and checking deliveries; and, in some cases, assisting in MyMeds services at ward-level.

The sample comprised 25 women and 11 men. Participants were aged between 25 and 65 (with a mean age of 41) and had worked for the NHS for between four and 40 years. The ratio of full-time to part-time employees was 5:1. One-to-one interviews were conducted face to face at the participants' place of work between July and October 2012. Interviews lasted between 45 and 120 minutes, and were recorded, 
transcribed and analysed thematically by researchers, using QSR NVIVO 10.0. A complementary 'key stakeholder' element of the research involved ten in-depth interviews with representatives of management, employee partnership groups and trade unions. These interviews provided context on the rationale and planning of the redesign process, but our discussion below focuses mainly on the perceptions and experiences of employees.

\section{Findings}

Our analysis focused on three key themes that appeared consistently in our interviews, all of which connect with the literature on Lean-type approaches in public service redesign: first, that while there were a number of different management rationales for the pharmacy redesign programme, there was limited scope for employee engagement in shaping the decision-making or implementation process; second, that the negative vision of Lean-type approaches fragmenting careers and 'curtailing' training and progression (see discussion of Carter et al. 2011b, above) was not fully realised, but that different groups of employees had varied postredesign opportunities for personal development; and lastly, that the redesign had a polarising impact on perceptions of other aspects of job quality, with those delivering services 'nearer to patients' reporting benefits, in sharp contrast to some colleagues redeployed to execute standardised tasks within the robotics-enabled distribution centre.

\section{Employee engagement in Lean redesign}


We have seen above that critics of Lean-type approaches in public services suggest that senior managers' decision-making can be flawed in first, assuming the necessity and efficacy of NPM reforms (as an alternative to, for example, making the 'business case' for additional investment in staff); and that work redesign around Lean principles is often seen as imposed from the top-down, contrary to the rhetoric of employee engagement that characterises the pro-Lean literature.

As suggested above, interviews with managers found some evidence of the preferencing of NPM solutions, but that this ran parallel with a more progressive rationale around the use of new technologies to deliver better pharmacy services 'nearer' to the patient. Senior managers tended to place the redesign programme, and its work reorganisation component, within the context of the existing MyMeds project that sought to use ICT to improve patients' access to both medicines and pharmacy expertise on wards. However, it was viewed as unrealistic to seek to persuade senior budget holders to provide additional staff in order to make MyMeds fully operational. Accordingly, while the objectives of the redesign programme were described in terms of improved patient-facing services - "the end goal was to deliver a [MyMeds] way of working, which is pharmacists on wards, technicians on wards" (Senior Manager) - there was an assumption that this needed to be achieved with "the same level of staffing numbers", leading senior programme managers to conclude that capital investment in new technologies was essential. Senior managers also cited evidence from the introduction of robotics in pharmacy services elsewhere in the NHS as facilitating co-ordination and eliminating duplication, with benefits for resource efficiency and employees' opportunities for development - "an answer to reorganising your service from lots of disparate bits into one service that 
you could then create a structure, succession planning, and educational development for your staff" (Senior Manager). Accordingly, from management's perspective, the rationales for the redesign programme were to some extent rooted in NPM assumptions around the capacity for new technologies and Lean-type approaches to deliver higher levels of performance without recourse to investing in additional staff, but also an overriding commitment to improving patient care.

Our evidence was clearer on another critique identified above - that Lean-type approaches in public services, far from 'engaging the enthusiasm of front-line staff' (Jones and Mitchell 2006: 6), can be seen by employees as being imposed without adequate consultation or engagement from the top-down. Senior managers pointed to consultation events and engagement with employees through well-established NHS partnership forums, but also acknowledged that the long gestation period of the redesign programme meant that information-sharing with staff had become disjointed.

"We'd involved partnership in the discussions and in the vision. If I was to go back and be very frank with what we were bad at was in this long hiatus where... we didn't do enough at telling the staff this is still it, this is the way we're going."

Senior Manager

Even the expression of regret quoted above described the problem in terms of management "not telling the staff", rather than reflecting on the potential for employees to play a full role in deciding and shaping reform processes. Many 
interviewees reported limited management-employee engagement and insufficient opportunities to discuss the redesign programme. Employees at all levels felt that staff consultation exercises had failed to influence the redesign programme. There was a common perception that decisions had been taken in advance by management and were imposed from the top down.

"I don't feel that I influence to any great degree, no. I don't feel I've got a very big voice... you're invited along to meetings to discuss, you know, redesign or whatever, to keep you informed and find out what your opinions are, but when you go along to them, you find that the decisions have really pretty much already been made, and it's really just telling you what's going to happen." Pharmacy technician

“We were asked for feedback, which we gave, but I don't remember ever seeing any of it being addressed."

Pharmacy technician

Accordingly, our interviews identified familiar concerns around the implementation of Lean-type approaches in public services - that despite rhetoric around the need for employee engagement and 'ownership' of reform processes (Radnor et al. 2012), consultation can be weak, while employees often feel that change is imposed from above. There may be problems in securing employee buy-in and commitment where management's rhetoric about the importance of consultation and collaboration is not made real. 


\section{Impacts on job quality: learning and progression}

A second key theme for our analysis focused on employees' different experiences of changing job quality in the form of opportunities for learning and progression. As we have seen above, the critical literature cites cases where Lean-type approaches have produced the fragmentation of jobs in public services, limiting opportunities for upskilling and career progression (Carter et al. 2013), while other studies have found some positive experiences of discretionary learning through collaboration with team members and line managers (Currie and Procter 2003). We have also described above managers' characterisation of the redesign programme as a progressive agenda designed to free staff to engage in more patient-facing work on wards. In interviews, senior managers consistently highlighted the potential for robotics technologies to eliminate repetitive, routine activities, allowing opportunities for staff (especially pharmacy technicians) to use their skills more effectively on hospital wards, and develop new learning through closer collaboration with pharmacists and other clinical professionals. Interviews with employees found that these opportunities for development had been realised, but only in some cases.

Among support workers, interviewees were split fairly evenly between those who felt that they received insufficient training upon redeployment and those who reported participating in new learning opportunities that they considered useful. The latter, more positive, responses came most often from support workers who had been redeployed to work closely with hospital ward-based pharmacy technicians as part of the MyMeds initiative. Some among the former group reported being unable to access training, due to lack of resources or staff to cover their absence. This, coupled with increasingly limited opportunities to rotate between teams and roles, 
limited their access to new skills. Furthermore, there was consensus among support workers that, even following training, opportunities for progression were severely limited, due to low turnover in higher-skilled (technician) posts and a freeze on additional recruitment. Undertaking full-time training towards technician grade could require support workers to leave their existing job, with no guarantee of a promoted post upon completion. Such uncertainty had proved a major disincentive to undertake training.

Technicians reported that, prior to the redesign programme, much of their training was informal and experiential, supported by more senior technicians and pharmacists. This informal training, alongside rotation through the different functions within hospital pharmacies, was seen as important in developing and maintaining technicians' skills. The redesign programme required that new roles for technicians were met with additional and more formalised training opportunities, and technicians reported having undergone an array of training, both formal and informal, to enable them to meet their altered responsibilities. Many technicians recalled positive experiences of retraining, in terms of improved skills utilisation within their job roles, and enhanced self-confidence, particularly in their relationships with patients and clinical professionals. However, almost as many reported problems in accessing training, with Lean staffing models again seen as restricting opportunities to take time off. Some technicians saw such restrictions on training as a barrier to career progression.

More generally, technicians again raised familiar concerns that, even with training, the 'leanness' of staffing in NHS pharmacy services meant that progression 
opportunities were at a premium. Of even greater concern was the view among both staff and managers that pharmacy technicians redeployed to the DC facility may be disadvantaged in terms of opportunities for progression. There were concerns that the specific skills required to work within a robotics-driven distribution centre were limited in their transferability, while opportunities to develop a wider range of skills (and the experience of working within inter-disciplinary teams in a hospital setting) were not available to these employees. Rotation between teams and tasks -

previously a common feature of pharmacy careers - had been restricted by a redesign programme that rationalised job roles, with negative impacts for some employees.

\section{Impacts on job quality: performance management and work intensification}

Just as employees' experiences of impacts on training and progression were mixed, so there was considerable variation in broader perceptions of changing job quality. One critique of Lean-type approaches that seemed to be of limited relevance in this case relates to Lean's potential to produce an intensification of top-down performance management. We have noted above that critics of Lean have identified its prioritisation of performance targets and deadlines as contributing to declining control and discretion for employees (Carter et al. 2012). Employees across all skill levels reported an element of working to deadlines, in that medicines had to be distributed and dispensed in accordance with planned patient discharge times. These discharge deadlines were seen as producing intermittent moments of intense pressure, particularly for support workers and technicians involved in large-volume distribution at the DC. However, whereas some studies of Lean-type approaches have identified new, intrusive and unhelpful forms of performance management as a 
side-effect, our interviewees generally saw discharge deadlines as an essential and relevant target, in line with the principles of high quality patient care.

Nevertheless, some support workers and technicians, across a range of work settings, again saw the leanness of staffing as contributing to moments of stress and intensification:

"If we have a full complement of staff, it's [the pace of work] probably still quite quick, because we have a lot of outpatients but we don't have as many discharges to do. But yeah, we still have...we have enough to get us through the day and to keep us working at a reasonable pace. But it gives you time to think about what you're doing as well. Where at the moment, I feel a lot of the time, you're just rush, rush, rushing to do things... And that puts an additional stress you, and that's when you do miss things and make mistakes."

Pharmacy technician

These views offer limited support for the critique detailed in our literature review above - that Lean-type approaches can produce work intensification with negative impacts on employee wellbeing in some cases (Carter et al. 2012). Yet, deadlines aside, many support workers reported greater control over how to prioritise work tasks. This was particularly the case for those working closely with ward-based pharmacists and technicians as part of the broader MyMeds project. The opportunity to engage in more challenging and collaborative work, rotating between a range of hospital-based environments, had produced considerable benefits in terms of learning, task variety and job satisfaction for these staff. 
"More interesting and more challenging, more complex... Because we're here and we're doing a rotation, you're getting to see every aspect... It's stuff you don't get to see. So I would certainly say more interesting, more varied, definitely...It's obviously more difficult because it's different."

Pharmacy support worker

These benefits were even more prominent in interviews with pharmacy technicians involved in the delivery of ward-based MyMeds services. Many of these interviewees valued both the opportunity to work closely with clinical professionals, and the sense that they were involved in the delivery of services to patients (although there was some variation in the extent to which these benefits had been realised, depending on the completeness of the MyMeds roll-out across different hospital sites).

In contrast, many DC support workers (and to some extent their technician colleagues) felt that their roles had become more detached from the delivery of pharmacy services. Just as DC-based staff reported limited opportunities to develop transferable skills outside their work in robotics-facilitated distribution, so some raised concerns that their new job roles offered relatively few opportunities for a broader range of interactions with clinicians, pharmacy colleagues, patients and ways of working.

As noted above, the effects of Lean-type approaches on employees' job quality is a major area of disagreement between advocates and critics of this type of reform. Employee perceptions of job quality also provided an important focus for our 
interviews, given that NHS managers saw the redesign programme, in combination with the MyMeds project that sought to relocate pharmacy staff nearer to the delivery of care to patients, as a route to improved skills utilisation and therefore better jobs. Our findings suggest considerable variation - perhaps even polarisation - in the experiences of pharmacy staff. Some staff, specifically those working within fully operational MyMeds wards, had indeed been 'freed' by new technologies to engage in more demanding and rewarding work 'nearer the patient', rotating between roles and learning through inter-disciplinary collaboration. Others based in hospital dispensaries and the DC found themselves with relatively few opportunities for rotation and reported a sense of isolation from mainstream pharmacy work (a view that was particularly strong among DC staff). And there was consensus that opportunities for learning and development that might eventually flow from the redesign programme had yet to be fully realised, partly because of a lean staffing model that made it difficult to find the time to train, and meant that employees could see few opportunities for advancement in the short to medium term.

\section{Discussion and conclusions}

The introduction of robotics technologies, the redesign of work organisation, and related changes to job roles described above were clearly informed by a commitment among senior managers and employees to delivering improved services nearer to the patient. There was a genuine belief among managers in the potential for new technologies to free staff to engage in patient-facing work, allowing for interdisciplinary learning and improved skills utilisation. However, our research also identified the influence of NPM-inspired ideas around the capacity of Lean-type 
approaches to deliver 'more with less'. We have seen above that the language of Lean - emphasising process redesign around new technologies and the elimination of duplication and waste - is increasingly prominent in reform strategies across the public sector (including the NHS). Some of the tensions and controversies around Lean-type approaches in public service employment were apparent in this case. There were familiar criticisms that technology-driven reforms were seen as imposed from the top-down. Crucially, front-line employees also consistently raised concerns about the leanness of staffing models, which were seen as limiting the full realisation of the redesign programme's potential benefits.

That said, some concerns identified in the critical literature on Lean-type approaches failed to materialise in this case. There was no imposition of new, inappropriate performance management; nor a wholesale process of job fragmentation or deskilling. Indeed, impacts on job quality could be described as variable, or even polarised. For a substantial group of staff, the redesign programme offered benefits, including the opportunity to collaborate with clinical professionals to provide services on wards and nearer the patient. Where complementary MyMeds technologies and processes were fully operational, there were opportunities for technicians and (to a lesser extent) support workers to rotate between teams, developing a range of skills and experience. However, a smaller group of employees described a sense of isolation from these opportunities. For those working in roles nearer the distribution technology (rather than nearer the patient), there were fewer opportunities for collaboration, role rotation and learning. And we should reiterate that employees across a range of job roles felt that a reliance on technology to try to deliver 'more with less', in place of sustaining and growing staff numbers, had negative impacts in 
terms of intermittent experiences of work intensification and limiting opportunities for training and progression.

There remains much debate about the relationship between Lean-type approaches and employee experiences of job quality and progression. Analyses of EU-level survey data suggest that Lean workplaces offer more by way of employee development and autonomy than do Taylorist modes of work organisation, but fall short of the opportunities provided in organisations defined by a commitment to 'discretionary learning'. The same research has demonstrated that Lean-type approaches are more prevalent in the UK than any other major EU labour market (OECD 2010). In this case, NHS managers should be commended for refraining from imposing the full impedimenta of Lean on the work of pharmacy staff. Far from the worst case scenario of intensified performance management and job fragmentation for all (Carter et al. 2012), there were winners and losers in this case there were benefits for some employees who were 'freed' from mundane work to concentrate on high-value tasks, but frustration for others who felt increasingly isolated from opportunities for learning and collaboration. Among the clear practical lessons to be drawn from our research is that managers, employees and other stakeholders should collaborate in order to identify ways to facilitate rotation between roles and teams for the broadest possible population of staff. In the longer term, there would be benefits in a strengthening of planning to facilitate training and progression, given the specific context of tight staffing budgets. However, our research also adds to the evidence on what appears to be a more fundamental disconnect between public sector managers and employees. For the former, new technologies, process redesign and Lean-type approaches are the only possible 
route to improved performance and better jobs in an era of employment austerity; for the latter both performance and job quality appear compromised by the leanness of staffing models. This tension is likely to remain a key theme in employment relations in the UK and beyond for as long as the public sector faces austerity and crisis. 


\section{References}

Bach, S. and Givan, R.K. (2011), 'Varieties of New Public Management? The Reform of Public Service Employment Relations in the UK and USA', International Journal of Human Resource Management, 22, 2349-2366.

Ben-Tovim, D.I., Bassham, J.E., Bolch, D., Martin, M.A., Dougherty, M., and Szwarcbord, M. (2007), 'Lean Thinking Across a Hospital: Redesigning Care at the Flinders Medical Centre', Australian Health Review, 31, 10-15.

Bonavia, T. and Marin-Garcia, J.A. (2011), 'Integrating Human Resource Management into Lean Production and Their Impact on Organizational Performance', International Journal of Manpower, 32, 923-938.

Carlborg, P., Kindström, D., and Kowalkowski, C. (2013), 'A Lean Approach for Service Productivity Improvements: Synergy or Oxymoron?', Managing Service Quality, 23, 291-304

Carter, B., Danford, A., Howcroft, D., Richardson, H., Smith, A., and Taylor, P. (2011a), 'All They Lack is a Chain: Lean and the New Performance Management in the British Civil Service', New Technology, Work and Employment, 26, 83-97.

Carter, B., Danford, A., Howcroft, D., Richardson, H., Smith, A., and Taylor, P. (2011b), 'Lean and Mean in the Civil Service: The Case of Processing in HMRC', Public Money and Management, 31, 115-122.

Carter, B., Danford, A., Howcroft, D., Richardson, H., and Smith, A., and Taylor, P. (2012), 'Nothing Gets Done and No One Knows Why: PCS and Workplace Control of Lean in HM Revenue and Customs', Industrial Relations Journal, 43, 416-432. 
Carter, B., Danford, A., Howcroft, D., Richardson, H., Smith, A., and Taylor, P. (2013), 'Taxing Times: Lean working and the Creation of (In)efficiencies in HM Revenue and Customs', Public Administration, 90, 83-97.

Currie, G. and Procter, S. (2003), 'The Interaction of Human Resource Policies and Practices with the Implementation of Teamworking: Evidence from the UK Public Sector', International Journal of Human Resource Management, 14, 581-599.

Exworthy, M. (2010) 'The Performance Paradigm in the English NHS', Eurohealth, $16,16-19$.

Jones, D. and Mitchell, A. (2006), Lean Thinking for the NHS. London: NHS Confederation.

Maroto-Sánchez, A. (2012), 'Productivity in the Services Sector: Conventional and Current Explanations', The Service Industries Journal, 32, 719-746.

McKinsey Center for Government (2012), Transforming Government Performance Through Lean Management. Washington: McKinsey Center for Government.

NHS Institute (NHS Institute for Innovation and Improvement) (2008), Quality and Service Improvement Tools: Value Stream Mapping. Online at: http://www.institute.nhs.uk/quality and service improvement tools/quality and s ervice improvement tools/process mapping - value stream mapping.html (viewed 14 May 2013).

OECD (Organisation for Economic Co-operation and Development) (2010), Innovative Workplaces: Making Better Use of Skills Within Organisations. Paris: OECD.

Osborne, S. (2010), The New Public Governance?. London: Routledge.

Pollitt, C. (2013), '40 Years of Public Management Reform in UK Central Government: Promises, Promises', Policy and Politics, 41, 465-480. 
Purkiss, R. (2008), 'Can Clinical Pharmacy Services be Quantified?', Pharmacy in Practice, 18, 6-7.

Radnor, Z. (2010), 'Transferring Lean into Government', Journal of Manufacturing Technology Management, 21, 411-428.

Radnor, Z. and Boaden, R. (2008), 'Editorial: Lean in the Public Services: Panacea or Paradox?', Public Money and Management, 28, 3-6.

Radnor, Z., Holweg M., and Waring J. (2012), 'Lean in Healthcare: The Unfulfilled Promise?', Social Science and Medicine, 74, 364-371.

Radnor, Z. and Osborne, S.P. (2013), 'Lean: A Failed Theory for Public Services?', Public Management Review, 15, 265-287.

Scottish Executive (2006), The Right Medicine: A Strategy For Pharmaceutical Care in Scotland. Edinburgh: Scottish Executive.

Scottish Government (2011), NHS Scotland Efficiency and Productivity Framework, 2011-2015. Edinburgh: Scottish Government.

Simonet, D. (2013), 'The New Public Management Theory in the British Health Care System: A Critical Review', Administration and Society, Online First, downloaded 17 December.

Sterling, A. and Boxall, P. (2013), 'Lean Production, Employee Learning and Workplace Outcomes: A Case Analysis Through the Ability-Motivation-Opportunity Framework', Human Resource Management Journal, 23, 227-240.

Womack, J.P., Jones, D.T., and Roos, D. (1990), The Machine That Changed the World. New York: Rawson Associates. 